OPEN ACCESS

Edited by:

Huanfa Yi,

Jilin University, China

Reviewed by:

Zong Sheng Guo,

University of Pittsburgh, United States

Yuan Cheng,

Peking University People's Hospital,

China

*Correspondence:

Min Cui

cuimw@hotmail.com

Ligong Lu

luligong1969@126.com

${ }^{+}$These authors have contributed equally to this work

Specialty section: This article was submitted to

Cancer Immunity and Immunotherapy,

a section of the journal

Frontiers in Immunology

Received: 01 September 2020 Accepted: 20 November 2020 Published: 21 December 2020

Citation:

LiW, Peng A, Wu H, Quan Y, Li Y, Lu L and Cui M (2020) Anti-Cancer Nanomedicines: A Revolution of

Tumor Immunotherapy.

Front. Immunol. 11:601497. doi: 10.3389/fimmu.2020.601497

\section{Anti-Cancer Nanomedicines: A Revolution of Tumor Immunotherapy}

\author{
Wei $\mathrm{Li}^{1 \dagger}$, Anghui Peng ${ }^{2 \dagger}$, Huajun $\mathrm{Wu}^{1}$, Yingyao Quan ${ }^{2,3}$, Yong $\mathrm{Li}^{2}$, \\ Ligong $\mathrm{Lu}^{2 *}$ and Min Cui ${ }^{1 *}$ \\ ${ }^{1}$ Department of General Surgery, Zhuhai People's Hospital, Zhuhai Hospital Affiliated with Jinan University, Jinan University, \\ Zhuhai, China, 2 Zhuhai Interventional Medical Center, Zhuhai Precision Medical Center, Zhuhai People's Hospital, Zhuhai \\ Hospital Affiliated with Jinan University, Jinan University, Zhuhai, China, ${ }^{3}$ Faculty of Health Sciences, University of Macau, \\ Macau, China
}

Immunotherapies have been accelerating the development of anti-cancer clinical treatment, but its low objective responses and severe off-target immune-related adverse events (irAEs) limit the range of application. Strategies to remove these obstacles primarily focus on the combination of different therapies and the exploitation of new immunotherapeutic agents. Nanomedicine potentiates the effects of activating immune cells selectively and reversing tumor induced immune deficiency microenvironment through multiple mechanisms. In the last decade, a variety of nano-enabled tumor immunotherapies was under clinical investigation. As time goes by, the advantages of nanomedicine are increasingly prominent. With the continuous development of nanotechnology, nanomedicine will offer more distinctive perspectives in imaging diagnosis and treatment of tumors. In this Review, we wish to provide an overview of tumor immunotherapy and the mechanisms of nanomaterials that aim to enhance the efficacy of tumor immunotherapy under development or in clinic treatment.

Keywords: tumor, immunotherapy, nanomedicine, nanotherapy, review

\section{INTRODUCTION}

Nanoparticles have become a promising strategy for anti-cancer treatment due to their inherent properties. To date, the clinical approvals for tumor therapy are organic materials, including liposomes (pegylated or non-pegylated) and albumin, while inorganic materials are used for tracking and molecular imaging functions, and only superparamagnetic iron oxide (SPIO) nanoparticles are approved in clinical (1). Nanoparticles for tumor therapy are mainly used for drug delivery, photothermal therapy, modification and preparation of engineered cells, imaging diagnosis, and lymph node (LN) tracing. Normally, nanoparticles are used as a drug-loading platform to improve the efficacy of existed anti-tumor agents. Nanoparticles loaded chemotherapeutic agents and targeting delivery into tumor sites have been applied to clinical treatment (2). However, the tumor immunotherapy based on nanoplatforms still stay at the stage of pre-clinical research. However, it is noteworthy that nanoparticles themselves trigger immunogenic tumor cell death and elicit both innate and adaptive immune responses for tumor control and metastasis prevention (3), which showed a broad-spectrum anti-cancer mechanism. 


\section{LIMITATIONS OF CONVENTIONAL TUMOR IMMUNOTHERAPIES}

Immunotherapy aims to activate immune system to discover and eradicate tumor cells and to inhibit tumor development durable by producing immunological memory $(4,5)$, while non-specific stimulate immune system directly enhances the reactivity to tumor antigens (6). Until recent years cancer immunotherapies have achieved higher objective response rates (ORR) in patients because of the promotion of $\mathrm{T}$ cell function by immune checkpoint blocking (ICB) with monoclonal antibodies (mAbs). Currently, ICB is often chosen as first-line therapy due to the long duration of response in some patients, even after cessation of therapy (Supplementary Table S1 and S2) $(7,8)$. However, there are two major obstacles in tumor immunotherapies, namely the low response rate and the severe immune-related adverse immunotherapy events (irAEs), which are still insurmountable issues in conventional tumor immunotherapy.

\section{Low Response Rate}

Although immunotherapy has shown substantial benefit in treatment of a variety of tumors and exhibit durable response, the majority of patients failed to respond to PD-1/PD-L1 blockers (9-12). 50\% patients with PD-L1 positive show tolerance after the initial response to PD-1/PD-L1 blockers, most patients will develop acquired resistance (13). Similarly, Anti-CTLA-4 has low level of ORR $(14,15)$. Moreover, the ORR of HDIL-2 monotherapy is $10 \%-19 \%$ with complete ORR of $6 \%-8 \%$ (16). Therefore, how to improve the ORR of immunotherapy and how to select appropriate indicators to predict the effectiveness of immunotherapy are the two hotspots of current research. At present, combined therapy is the major way to improve clinical response rate, such as the combination of different ICBs (17-20), the combination of various immunotherapies including tumor vaccines, CAR-T, and IL-2, immunotherapy combined with antiangiogenic therapies (21) and immunotherapy combined with chemotherapy (12,22-24). Diverse chemotherapeutics can induce the expression of PD-L1 through distinct mechanisms $(25,26)$, so the chemotherapy combined PD-L1 inhibitors may produce a synergistic effect. Combining nivolumab with radiotherapy could induce immunosensitization to improve the efficacy of PD-1 blocker $(27,28)$, while immunotherapy combined with small molecule inhibitors therapies reflects immunomodulatory effects, such as the increase of tumor antigenicity and the promotion of $\mathrm{T}$ cell infiltration in tumors (29-31). Overall, given the current clinical projects, except the optimization of the current drug combinative strategies, new platform should be founded to improve the treatment status, reduce side effects and recognize the tumor-specific antigens by engineered lymphocyte.

\section{Immune-Related Adverse Events}

Immunotherapy often results in irAEs $(14,32)$, whose pathogenesis can be comprehended by the immune-pathophysiology that excessive and systemic immune system activation can occur at any point during treatment course (33-35). Generally, irAEs include skin toxicity, diarrhea, colitis, pneumonia, liver toxicity, and endocrine system toxicity, and the severity of irAEs is divided into $1-4$ grades (36). Approximately $30 \%$ patients with melanoma who had accepted the CTLA-4 blocking strategy developed to toxicity grades 3-4, suggesting that the inhibitor activated the systemic immune response rather than tumor-specific $\mathrm{T}$ cells (14). In most cases, the combined therapy increases the incidence of irAEs $(17,31,37,38)$. Patients with asymptomatic can be carefully observed and followed up. If it cannot reach a higher level stage and relieve the patients' suffering, withdrawal temporarily or permanently and medical interventions including steroids and immunosuppressive agents are required. Notably, the potential risk of toxicity should not outweigh the overall survival (OS) benefit.

\section{APPLICABLE SYSTEMS OF NANOMODIFIED IMMUNOTHERAPY}

As a versatile platform, nanoparticles can not only be loaded with agents to improve their efficacy but also play a role of therapeutic media themselves (Table 1). In recent years, nanomedicine has continued to solve existing problems and has achieved the desired therapeutic effects in cancer immunotherapy.

\section{Drug Delivery Systems}

In terms of ICB and cytokine therapies' low affinities with the targeted proteins and the obstacle of precise delivery, it is necessary to improve the targeting and the controlled releasing

TABLE 1 | The types and functions of nanoparticles commonly used in clinical trials.

\begin{tabular}{|c|c|c|}
\hline Particle type & Application in clinical trials & Functions \\
\hline \multicolumn{3}{|l|}{ Organic NPs } \\
\hline Cyclodextrin NPs & CRLX101 & $\begin{array}{l}\text { improve drug solubility } \\
\text { deliver drug to tumor }\end{array}$ \\
\hline Liposome NPs & $\begin{array}{l}\text { Tecemotide, Lipo-MERIT, } \\
\text { DPX-0907, DPX-Survivac, } \\
\text { OncoQuest-L, Lipovaxin MM, } \\
\text { ISCOMATRIX, AS15, JVRS- } \\
\text { 100, }\end{array}$ & $\begin{array}{l}\text { improve drug-loading } \\
\text { efficiency } \\
\text { provide efficient cell affinity } \\
\text { increase cellular uptake }\end{array}$ \\
\hline Polymeric NPs & $\begin{array}{l}\text { CHP-NY-ESO-1, IMF-001, } \\
\text { ZYC300 }\end{array}$ & deliver antigen \\
\hline Solid Lipid NPs & ONT-10 Vaccine & adjuvant \\
\hline Exosomes NPs & Dex2 & $\begin{array}{l}\text { extracellular vesicles } \\
\text { target and dock to recipient } \\
\text { cells } \\
\text { stimulate CD8+ and CD4+ T } \\
\text { cells }\end{array}$ \\
\hline $\begin{array}{l}\text { Autophagosome } \\
\text { NPs }\end{array}$ & DRibbles & $\begin{array}{l}\text { induce B-cell proliferation and } \\
\text { activation } \\
\text { induce antibody production } \\
\text { induce cytokine secretion } \\
\text { antigen cross- presentation }\end{array}$ \\
\hline Virus-Like NPs & Melan-A VLPs & $\begin{array}{l}\text { restore immune response } \\
\text { Induce CTL response } \\
\text { antigen cross- presentation }\end{array}$ \\
\hline Tumor lysate & WDVAX & activate the immune system \\
\hline
\end{tabular}

NPs Inorganic NPs

Gold NPs Colloidal gold deliver protein biologics 
capabilities of anti-cancer drugs to make them work in specific sites and minimize off-target effects (39). Surprisingly, as a drug carrier, nanoparticles increase the biocompatibility and solubility of reagents, prolong their blood circulation time to provide unique advantages in the precise delivery of drugs to target sites (Figure 1). Briefly, the nanomodified immunotherapies reduce peripheral toxicity and side effects, making clinical treatment more compliant and precise.

AlbiVax is a novel nanovaccine complex that the antigen is conjugated to Evans blue and can be self-assembled in combination with albumin in vivo. Compared with incomplete Freund's adjuvant, AlbiVax had an almost 100-fold higher efficacy in delivering antigen to LNs, and its ability to elicit immunological memory of peripheral antigen-specific $\mathrm{CD}^{+} \mathrm{T}$ cells was approximately 10 times higher than that of incomplete Freund's adjuvant. AlbiVax restrains the growth of various tumors, and the combination of AlbiVax with anti-PD-1 agents Abraxane enhances immunotherapy and eradicates most tumors (40). Encapsulation of anti-PD-1 antibodies with PLGA nanoparticles improves the anti-tumor effect but exhibits higher mortality due to the overactivation of $\mathrm{T}$ cells, which can be reversed by reducing dose (41). A multifunctional immunoliposomes named CAT@aPDL1-SSLs promoted the delivery and accumulation of anti-PDL1 antibodies in tumor tissues to activate the infiltration of $\mathrm{CD}^{+} \mathrm{T}$ cells at the tumor site with low systemic toxicity (42). In addition to direct drug delivery, nanoparticles package small interfering RNAs (siRNAs) targeting PD-1 and T-cell immunoglobulin mucin 3 (TIM-3) to restore T cell immunity and sensitize the response of cancer cells to T cell killing $(43,44)$. Loading the PD-L1 trap plasmid into a lipid-protamine-DNA nanoparticle enhanced the local level of PD-L1 trap in tumor microenvironment (TME) but did not induce the appearance of Th17 cells in spleens, indicating that this formulation was better tolerated and had a lower tendency to induce irAEs than the unmodified plasmid (45). Collectively, targeted delivery of agents is based on the enhanced permeability and retention (EPR) effect of nanomaterials and abnormal tumor blood vessels, but the characteristics of nanomaterials have a profound and lasting effect due to their surface modifiability.

\section{Regulation of the Hypoxic Microenvironment}

Hypoxia is a hallmark of TME that induces the tumor resistance to immunotherapy $(42,46,47)$. Preclinical and clinical data indicate that hypoxia can significantly reduce the efficacy of antitumor immunity (48-51). This mechanism includes the following immunity reactions: a) Hypoxia limits infiltration and proliferation of anti-tumor immune cells; b) Hypoxia acts as an intrinsic immunosuppressive for $\mathrm{T}$ cells to inhibit tumorkilling function; c) Hypoxia up-regulates the expression of PDL1, which promotes the binding of HIF-1 $\alpha$ to a transcriptionally active hypoxia-response element (HRE) (50, 52); d) Hypoxia induces high expression of forkhead box P3 (FOXP3), transforming growth factor- $\beta$ (TGF- $\beta$ ) and CC-chemokine ligand 28 (CCL28) that selectively attracts regulatory $\mathrm{T}$ cells (Treg) and increases their functions, which results in antigen tolerance and suppression of the response to effector T cells; e) Hypoxia reduces the production of interferon- $\gamma($ IFN- $\gamma$ ) and interleukin-2 (IL-2) by both CD4+ and CD8+ T cells (52). Therefore, reverse the hypoxic TME may potentially increase the immune response.

Nanotechnology has been increasingly used to reverse tumor hypoxic microenvironment $(42,53,54)$. Modified nanoparticles could attenuate the unfavorable factors by normalizing oxygen levels through tumor vascular normalization $(55,56)$, external oxygen delivery, capture and delivery of oxygen from the lungs and generation of oxygen through catalysis of water (47).

Vascular function dictates the efficacy of immunotherapy. Tumor vascular normalization is an important measure to reduce the hypoxic microenvironment (57). Some pure inorganic nanoparticles, including gold or silver nanoparticles, can modulate tumor blood vessels $(58,59)$. Moreover, many reagents (60) and siRNAs (61) targeting blood vessels can be loaded into nanoparticles to retain vascular normalization (62). In addition, the remodeling of blood vessels increases the enrichment and infiltration of anti-tumor drugs and $\mathrm{GrzB}^{+}$effector $\mathrm{T}$ cells in tumors, which sensitize tumor to immunotherapy $(63,64)$.

Since intelligent nanoparticles respond to TME, they may induce the generation of oxygen. $\mathrm{MnO}_{2}$-based nanoplatforms
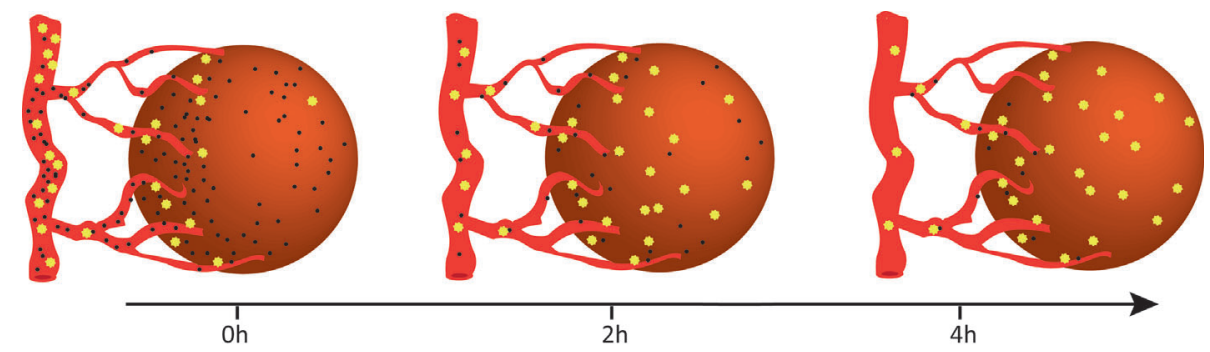

* Nanoparticles $\bullet$ Small molecule reagent

FIGURE 1 | Enhanced retention of nanoparticles. Compared to small-molecule drugs, nanoparticles appear to be gradually enriched in tumors and maintained for a longer period of time. 
could react with excessive endogenous $\mathrm{H}_{2} \mathrm{O}_{2}$ in TME to generate oxygen in situ and to overcome hypoxia limitations for cancer therapy $(65,66)$. A novel TiO-porphyrin nanosystem (FATiOPs) was designed by encapsulating TiO-porphyrin into folic acid liposomes. FA-TiOPs can photosplit water to produce oxygen, which overcomes hypoxia in TME, boosts specific anticancer effects while being harmless to normal tissues, especially under acidic conditions (67). FeSiAuO contains $\mathrm{Fe}_{3} \mathrm{O}_{4}$, mesoporous $\mathrm{SiO}_{2}$ and magnetic $\mathrm{Au}_{2} \mathrm{O}_{3}$, which decompose into $\mathrm{O}_{2}$ in TME under light irradiation (68).

Oxygen-carrying is a direct strategy in which nanocarriers load oxygen in oxygen-rich areas and release oxygen in hypoxic areas depending on the partial oxygen pressure (Figure 2) (53). Perfluorocarbon is a safe $\mathrm{O}_{2}$ carrier that has been already demonstrated in clinic, and the encapsulation of perfluorocarbon with albumin enhanced its accumulation in the tumor site and rapidly released the oxygen that was physically dissolved (69). Fluorocarbon-functionalized nanoparticles enhanced the effects of both photodynamic therapy (PDT) (70) and oxygen-sensitive antitumor drugs (71) by increasing tumor oxygenation. Besides, perfluorocarbons have entered clinical trials for ischemia and imaging theranostic strategies to ensure that the simple $\mathrm{O}_{2}$ transport system can be rapidly and easily transformed into clinical applications. Hemoglobin $(\mathrm{Hb})$ is another appreciating functional material for the development of oxygen-carrying nanoparticles. Hemoglobin nanoparticles (H-NPs) are assembled after re-emulsion. They are Hb-based oxygen nanocarriers that attenuate the hypoxia-induced decrease in decitabine activity and sensitize renal cell carcinoma to combination therapy of decitabine with oxaliplatin (72). Overall, hypoxic TME is a critical variable for immunotherapy. The development of nanomaterials targeting the hypoxic TME is one of the fastest growing branches of nanomedicine.

\section{Nano-Based Photothermal Therapy Induced Tumor Immune Response}

By effectively generating lethal doses of heat under near-infrared (NIR) light irradiation, photothermal therapy adopts material with high photothermal conversion efficiency to kill tumor cells $(73,74)$. The nanomaterials that initially provided photothermal therapy were mainly precious metals, but they have gradually developed into nanocarbons, metal organic compounds and organic dyes. For instance, PLGA nanoparticles loaded with indocyanine green (ICG) stimulate physicochemical and physiological changes in TME under mild heating, leading to increased infiltration of chondroitin sulfate proteoglycan-4 (CSPG4)-specific CAR T cells (73). Silica sealed by gold nanoshells (AuroShell) is the only inorganic material approved by Food and Drug Administration (FDA) for clinical photothermal therapy (75). AuroShell particles can be passively accumulated in solid tumors through the vasculature and were demonstrated safe when they were used systemically in focal ablations in prostate (74).

Intriguingly, tumor immune effect induced by photothermal therapy has been recognized. Photothermal therapy induces deep tissue immunogenic cell death, potentiates cancer immunotherapy and synergistically enhances immune efficacy (Figure 3). Gold nanostars (GNS) induced the anti-tumor immune response following the highly immunogenic thermal death of cancer cells, and the combination of GNS-mediated photothermal therapy with ICB reversed tumor-mediated immunosuppression (76). $\mathrm{Al}_{2} \mathrm{O}_{3}$ nanoparticle coating with polydopamine acts as an adjuvant for photothermal therapy, triggering a series of powerful cell-mediated immune responses to eliminate residual tumor cells and reduce the risk of tumor recurrence (77).

The therapeutic outcome of photothermal therapy is limited by the degree of light transmission (78), while the deep internal
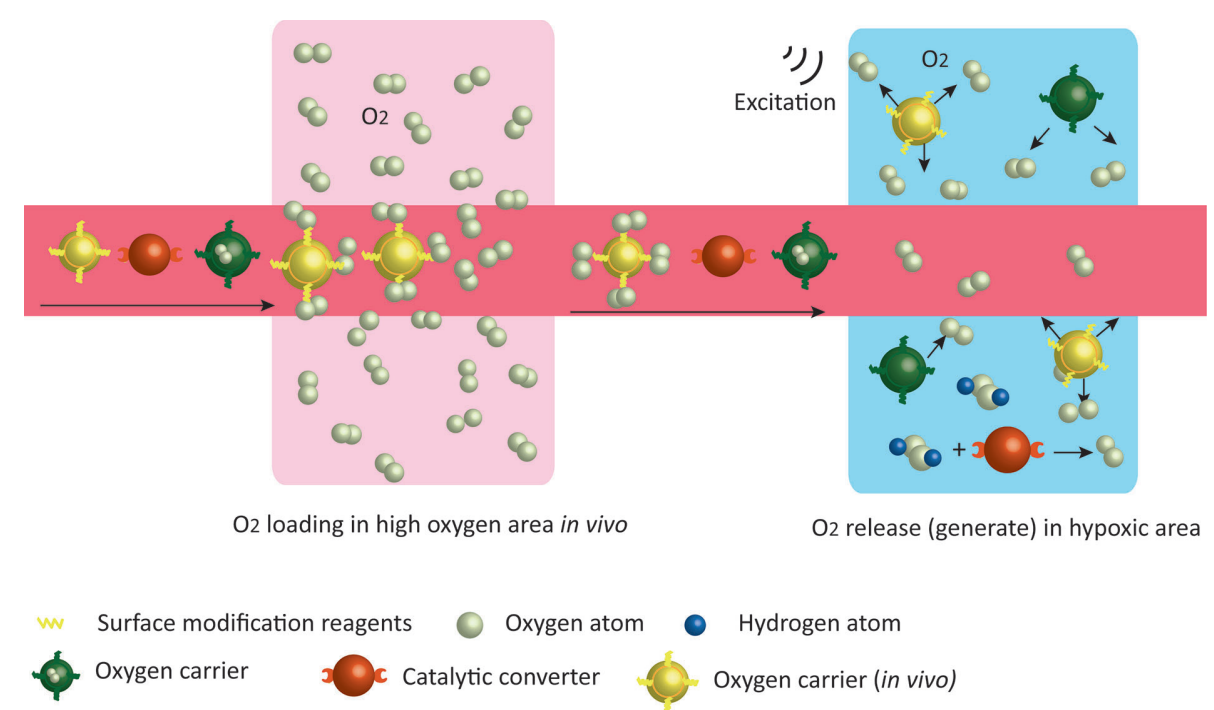

FIGURE 2 | Strategies of nanoparticles to increase tissue oxygen content. Oxygen carriers wrap $\mathrm{O} 2$ in vitro, or bind $\mathrm{O} 2$ in high oxygen areas in vivo and release them in low oxygen environment. Nanoparticles with catalytic effects react with excessive endogenous $\mathrm{H} 2 \mathrm{O} 2$ in the TME to generate oxygen. 


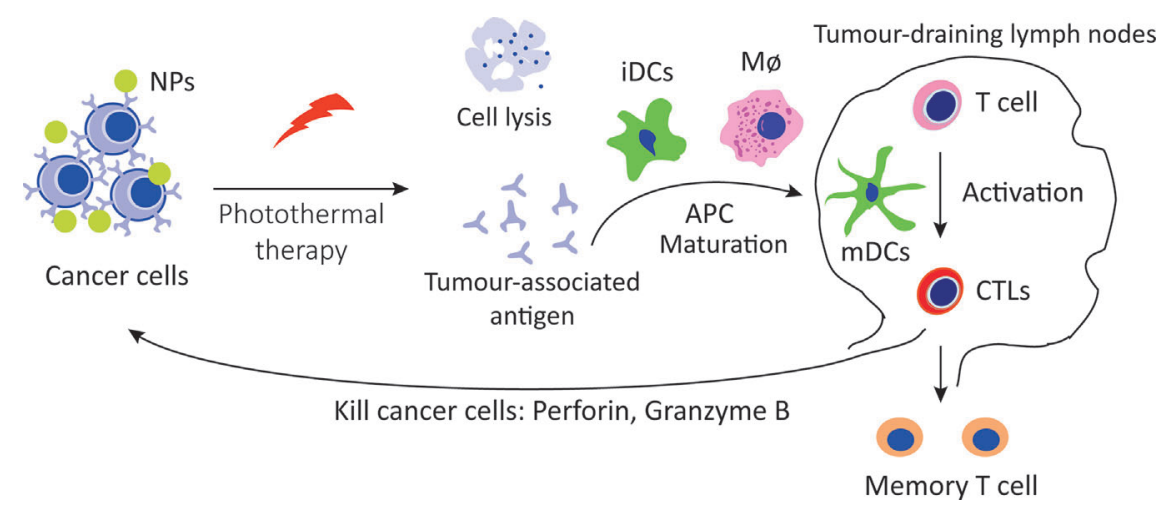

FIGURE 3 | Immunotherapy induced by photothermal therapy. Photothermal therapy increases the tissue immunogenic cell death and release antigens, which are presented to T cells by DCs and macrophages, enhance the recognition and killing to tumor cells.

area of the tumor lacks lymphocytic infiltration and experiences in various immune escape mechanisms (3). However, these issues could be solved by the combined nano-based photothermal therapy with immunotherapy. A multiplex nanoparticle assembled by a NIR photosensitizer named IR780 and an IDO inhibitor named NLG919 enhanced accumulation in the tumor site via passive targeting, increased the infiltration and differentiation of $\mathrm{T}$ cells into $\mathrm{CD}^{+} \mathrm{T}$ cells, suppressed the tumor margin beyond the border of effective photothermal therapy and strengthened the immune response to inhibit the distal tumor (78). The assembly of gold nanoparticles into fluid liposomes produced photothermal sensors that have NIR-I and NIR-II biological windows and respond to different absorptions of red light. NIR-II light activates both innate and adaptive immune responses, achieves effective tumor control (3) and triggers more homogeneous and deeper immunogenic cancer cell death than NIR-I light. In addition, photothermal therapy facilitates the accumulative and effective function of CAR-T cells within solid tumors by reducing tumor interstitial pressure, increasing blood perfusion and releasing antigens (73). Briefly, these findings demonstrate the great potential of nano-based photothermal therapy in immunotherapy.

\section{Reprogramming the Immune Microenvironment}

The efficacy of immunotherapy depends on the infiltration of immune cells and immune factors in TME. Tumor cells reprogram the microenvironment to facilitate immune escape and induce immunotherapy tolerance. Therefore, reversing the immunosuppressive microenvironment is an insightful perspective for the improvement of immunotherapy. The increasing numbers of multifunctional modified nanoparticles are being created, which shows us a diversity of anti-tumor mechanisms. In addition to a role of carrier, nanoparticles also directly activate immune cells to participate in antitumor responses.

At present, most of the nanoparticles that activate immune cells are coupled with immune activators, such as ICB molecules $(34,79$, 80 ) and tumor vaccines. Luo and colleagues first discovered that
$\mathrm{Fe}_{3} \mathrm{O}_{4}$ NPs act as immunopotentiators to stimulate dendritic cell (DC)-based immunotherapy and to potentially activate macrophages and $\mathrm{T}$ cells. $\mathrm{Fe}_{3} \mathrm{O}_{4}$-OVA vaccines successfully inhibit the subcutaneous growth and lung metastasis of melanoma (1). Because iron-based nanomaterials have been approved by FDA, they are expected to be used in clinical tumor treatment in future. Nanospheres, as a new vaccine adjuvant, elicited prominent antigen cross-presentation effects on DCs and bone marrow dendritic cells (BMDCs), enhanced humoral and cellular immune responses in vivo $(81,82)$. Although the application of ICB is impeded by TME, the modified nanoparticles co-loaded with CRISPR/Cas9 and paclitaxel (PTX) to reduce Tregs and repolarize tumor associated macrophages (TAMs), which can reverse the TME and enhance anti-tumor immunity (83). Collectively, we can continuously obtain the optimal efficacy of immunotherapy thanks to the nanomaterials' function of crosstalk reprogramming and immune cells activation in various ways.

Interestingly, some nondrug-loaded nanoparticles have been shown to directly modulate the immune microenvironment. Zhang et al. assembled ursonic acid with liposomes into nanoparticles to increase the solubility, which modulated TME by reducing $\mathrm{CD}^{+} \mathrm{CD} 25^{+}$Foxp $3^{+}$Tregs, and this reduction was correlated with the inhibition of STAT5 phosphorylation and the reduction of IL-10 expression (81). Systemic exposure to nanoparticles enabled transient immune recognition of tumor, increased the number of immune cells, such as NK cells, monocytes, $\mathrm{CD}^{+} \mathrm{T}$ cells, and $\mathrm{CD}^{+} \mathrm{T}$ cells, reconfigured $\mathrm{TME}$ immune system and delayed tumor growth; Of note, all of these changes were independent of antibody therapeutic activity and therapeutic payload (84). Natural nanoparticles can be easily obtained with their application prospects. Nanoparticles extracted from cuttlefish ink (CINPs) increase $\mathrm{CD}^{+} \mathrm{T}$ cells and repolarize M2 macrophages to the M1 phenotype through activation of the MAPK pathway. CINPs almost completely restrained tumor growth when synergizing with the photothermal effect, which induces tumor-specific antigen release (85). In general, the immunosuppressive microenvironment of solid tumors represents a severe obstacle for immunotherapy. However, nanomedicine 
potentiates the effects of TME modulation by activating immunosupportive cells and inhibiting immunosuppressive cells.

In addition to tumor tissues, $\mathrm{LN}$ is another important target for nanoparticles to produce anti-tumor effects. For instance, compared with its parent compound, the structure-optimized CpG-DNA/peptide vaccine increases the efficiency of $\mathrm{T}$ cell initialization and improves anti-tumor function and reduces systemic toxicity due to its advantages of a significant increase in $\mathrm{LN}$ accumulation and a decrease in systemic diffusion (86). Nanoparticle-bound tumor-associated antigens can transform immunosuppressive environment of the LNs draining the tumor into the more immunogenic environment. Compared with nontargeted vaccines, vaccines that target tumor draining lymph nodes (tdLN) can regress tumors and retain a higher host survival rate, because they induce intense cytotoxic CD8 ${ }^{+} \mathrm{T}$ cells reactions (87).

Nanomaterials increase anti-tumor effects in the progress of both cell-mediated immunity and humoral immune regulation. For one thing, multiple nanoparticles effectively stimulate the proliferation of $\mathrm{CD}^{+}$and $\mathrm{CD} 8^{+} \mathrm{T}$ cells, thereby further promote the production of antibodies, which together trigger more dramatic humoral and cellular immune responses than free antigen alone (88). For another, some nanoparticles can directly increase the binding robustness of antibodies. As a result, manipulating the chemistry of polyanhydride nanoparticles promotes the differential kinetics of antibody titer, affinity and epitope specificity development, and eventually, induces continuous and mature antibody responses (89).

\section{Nano-Engineered Cells}

Currently, viral delivery vector is a major medium of chimeric antigen receptor (CAR)-engineered $\mathrm{T}$ cells, which induce permanent expression of CAR but may cause serve adverse reactions (90). Nanotechnology promotes the adoptive $\mathrm{T}$ cell therapy, effectively delivers CAR cargo to T cells or other effector cells, and then quickly programs $\mathrm{T}$ cells to recognize tumor cell antigens (91). Nanocarriers present TCR stimulation signals or pro-survival cytokines, accelerate $\mathrm{T}$ cell transduction in vivo and improve their survival rate (91). Biodegradable nanomaterials take advantages of structural flexibility, the ability to deliver soluble paracrine to $\mathrm{T}$ cells and surface-bound molecules will be lost over time, which prevents excessive activation of T cells (92). In a word, nanotechnology-based CAR T cell modification is a promising approach to improve the efficacy of adoptive cell therapy (Figure 4).

Nanotechnology efficiently delivers pEGFRvIII-CARs to Jurkat $\mathrm{T}$ cells transiently and expresses EGFRvIII-CAR on the transfected cell membrane, enabling Jurkat $\mathrm{T}$ cells specifically to recognize and bind to EGFRvIII-positive tumor cells (93). Nanoparticles which encapsulated with an A2aR-specific small molecule antagonist attached to the surface of CAR-T cells in vitro had no effect on the recognition of target cells, IFN- $\gamma$ secretion, cell cytotoxicity or migration but increased the active targeting of the tissue of interest and ameliorated intratumoral $\mathrm{T}$ cell hypofunction (94).

Therapeutic nanoparticles click into the surface of CAR-T cells modified with IL-13 targeting quadruple mutant (TQM-13), which increases the affinity with glioblastoma (95). Nanoparticles encoding FOXO1 gene promote the transformation of effector $\mathrm{T}$ cells into memory cells (96). Compared with traditional methods, ionizable lipid nanoparticles deliver mRNA to $\mathrm{T}$ cells to induce CAR expression in an equal level, but decrease cytotoxicity and enhance the potential of mRNA-based CAR-T cell engineering methods (90). Conjugating IL-2 to liposomes is inclined to target adoptive cell therapy (ACT) cells and induce ACT-T cell proliferation in tumor-tolerant mice, proving the feasibility of repetitive functional targeting of $\mathrm{T}$ cells in vivo (97). Dextrancoated superparamagnetic iron oxide nanoparticles have been designed for the expansion of T cells, while MHC-Ig antibodies and anti-CD28 antibodies are conjugated to them to provide antigen-specific and co-stimulatory signals. This Nano-aAPC provoked the activation of tumor-specific $\mathrm{T}$ cells through "enrichment plus amplification" (98).

In addition, nanoparticles can self-assemble into CAR-like complex which activate $\mathrm{T}$ cells while targeting tumors. Bai et al.

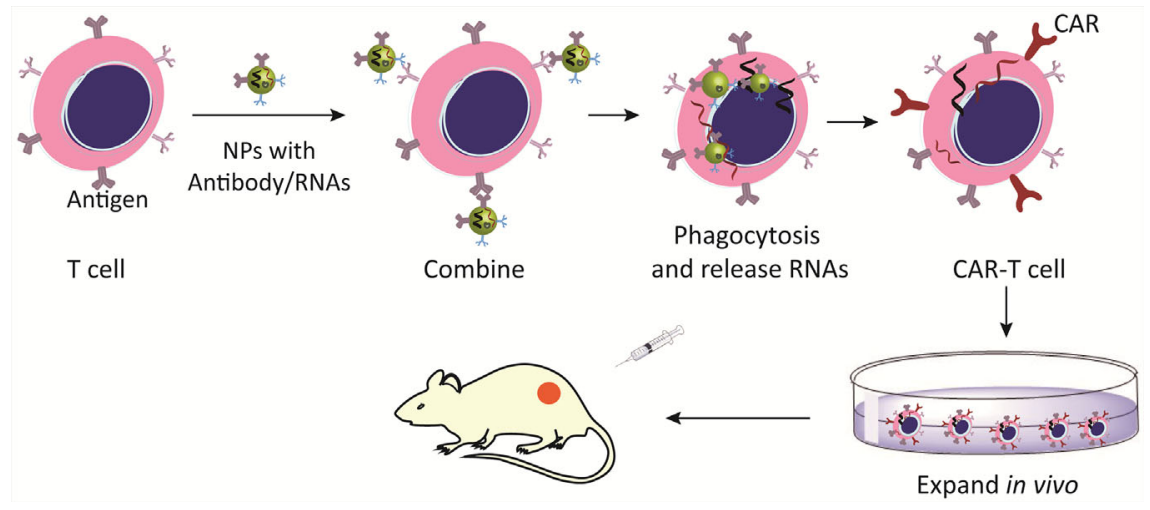

FIGURE 4 | Nanomaterials activate and expand adoptive T cells. Nano-modified CAR-T cells increase the expression of CAR antigens and improve the recognition of tumor cells. 
developed CAR-like multivalent aptamer nanoparticles which were assembled with CD28 RNA aptamer and the tetramer of CTLA-4 RNA aptamer, as well as a folic acid labeled single stranded DNA fragment in a stable nucleic acid three-way junction scaffold. These nanoparticles increase $\mathrm{T}$ cell proliferation, reverse the inhibitory effect of IL-2 secreting caused by exogenous B7.1 molecules on $\mathrm{T}$ cells in vitro and promise a novel approach to develop a multi-functional design of aptamer drugs with potential CAR-like characteristics to enhance the safety of CAR-T cell immunotherapy (99).

Nanoparticles also harbor both the function of NK cells modification (100) and the potential of CAR-NK therapy achievement. For one thing, nanoparticles promote the transfection of siRNA to NK92 cells which have been used for NK-based cancer immune therapy in clinical trials (101); For another, nanoparticles are used to enhance the expansion of adoptively transferred NK cells. For instance, particles prepared from the plasma membrane of K562-mb21-41BBL cells that express 562BBL and membrane-bound IL-21 (PM21 particles) induce PBMCs from healthy donors and patients with AML to produce specific NK cell expansion (102).

\section{Combination of Nanotechnology With Monoclonal Antibodies Therapy}

The combination of Abs with nanomedicine includes nanobiosensors, Ab-based nanomachines and active targeted drug delivery systems (103). Some tumor-specific markers have been discovered, and the usage of corresponding Abs modified nanoparticles can transform the passive targeting into active condition and functionalize them as "guided missiles" to increase the specificity of enrichment in tumor sites and to minimize damage to healthy tissues. For example, anti-CD133 Abconjugated SN-38-loaded nanoparticles recognize CD133 on the surface of colorectal cancer cells, thereby increasing the targeting of nanometers (104). CD-340-conjugated DOXloaded PLGA nanoparticles preferentially deliver drug to breast cancer tissue, and reduce DOX-mediated cardiotoxicity due to its tumor-specific distribution (105). In addition, antibodies for more markers were conjugated to a variety of nanoparticles which have been extensively verified in preclinical studies. Most of them have shown good targeting and anti-tumor activity. For example, daunorubicin-loaded CdTe QDs conjugated to antiCD123 mAbs (DNR-CdTe-CD123) treatment was designed for high-risk myelodysplastic syndromes (MDS) (106), the nanocomposite displayed higher inhibition rate and apoptosis rate in MDS cells than monotherapy, enhanced the therapeutic efficacy and reduced the side effects of daunorubicin. Genetically engineering cell-derived exosomes with anti-CD3 and antiHER2 antibodies (aCD3-aHER2 SMART-Exos) dually target T cells and HER2 ${ }^{+}$breast cancer, selectively inducing HER2expressing tumor-specific immunity and activating cytotoxic $\mathrm{T}$ cells toward attacking breast cancer cells (107).

At present, some clinically approved drugs are gradually being nano-sized to improve their therapeutic effects. Herceptinconjugated paclitaxel loaded PCL-PEG worm-like nanocrystal micelles (PTX@PCL-PEG-Herceptin) remained relatively stable in the circulation and in TME. PTX@PCL-PEG-Herceptin greatly enhanced the binding robustness of the nanoparticle to the HER2 ${ }^{+}$ breast cancer cells, enriched target cells rapidly and protected normal tissues from the toxic effects (108). The conjugation of HER2 protein 1-146 with cholesteryl pullulan (CHP) nanoparticles (also named CHP-HER2 vaccine) was safer than HER2 protein 1-146 used only, the complex induced HER2specific $\mathrm{CD}^{+}$and $\mathrm{CD}^{+} \mathrm{T}$ cell immune responses in patients who received four to eight vaccinations (109).

Anti-EGFR Abs are mainly used to bind gold nanoparticles based on active targeting function $(110,111)$, and phase I clinical trials have been launched on the basis of a large number of preclinical studies. For example, anti-EGFR-immunoliposomes loaded with doxorubicin (C225-ILs-dox) were used for patients with relapsed or refractory high-grade gliomas (NCT03603379). Anti-EGFR ILs-dox nanoparticles were designed by pegylated liposomes which encapsulated doxorubicin into antigen-binding fragments (Fab') of cetuximab, this nanoplatform was well tolerated, and showed more effective than non-targeted liposomes at destroying EGFR-overexpressing target cells because of its active and specific internalization (NCT01702129) (112).

\section{POSSIBILITIES OF NANOMATERIALS IN CLINICAL TUMOR IMMUNOTHERAPY}

A large number of nanomaterials have been synthesized for tumor treatment in clinical trials (Supplementary Table S3). However, there are few approved in clinical applications. Only liposomes and albumin carriers were formed into stable dosage types. The clinical nanomaterials applied for tumor therapy are listed in Supplementary Table S4.

Liposome is an outstanding drug delivery platform due to its biocompatibility and drug encapsulating efficiency (100), which can be loaded with hydrophobic and hydrophilic molecules. Immunoliposomes directly target tumors to provide a bystander killing effect through diffusion of loading agents to neighboring tumor cells $(42,112)$. Liposomes have been extensively applied in clinical management of cancers. The first nanomedicine for tumor clinical treatment is doxorubicin (Doxil ${ }^{\mathrm{TM}}$ ), a PEGylated longcirculating liposome loaded with doxorubicin approved in 1995, whose main indications are advanced ovarian cancer, multiple myeloma and HIV-combined Kaposi's sarcoma (113). Nanoplatform based vincristine sulfate liposome (Marqibo ${ }^{\mathrm{TM}}$ ) was proved for treatment of adult patients with Philadelphia chromosome-negative $\left(\mathrm{Ph}^{-}\right)$acute lymphoblastic leukemia (ALL) $(114,115)$ while Irinotecan liposome $\left(\right.$ Onivyde $\left.^{\mathrm{TM}}\right)$ for metastatic pancreatic cancer (116). Other liposome-based nanodrug in tumor treatment includes daunorubicin liposome $\left(\right.$ DaunoXome ${ }^{\circledR}$ ), doxorubicin liposomes, cisplatin liposomes and so on. Furthermore, modification of nano-liposomes increases the functional characteristics of the nano-drug platform with greater targeting effect. Temperature-sensitive liposomes could passively load with gemcitabine and copper complex to release drugs with tumor vasculature in response of ultrasound hyperthermia (117). Oleuropein loaded folate-targeted-PEG liposomes was prepared 
by the method of film hydration-cum-extrusion technique which enhanced the anti-cancer effect of oleuropein (118).

Albumin is a well-tolerated material with the advantages of highly solution and stability, no toxicity, no immunogenicity and easily chemical function (119). Albumin could protect circulating nanoparticles from the recognition and elimination of mononuclear phagocytic systems with half-life of 19 days, and they can avoid renal clearance because of the reabsorption by receptor-mediated endocytosis in the renal proximal tubule (120), thus albumin-based nanoparticles can be enriched in solid tumor tissues based on their increased consumption by cancer cells and the interaction with TME (121). All of these processes make nanoparticles become helpful carriers for anti-cancer agents. Onafuye and colleagues designed doxorubicin-loaded albumin nanoparticles by desolvation and crosslink using glutaraldehyde which could reverse transporter mediated drug resistance, whereas other nanocarrier systems have not found the similar effect (122). Choi and colleagues prepared inhalable self-assembling doxorubicin albumin nano-system which was treated with tumor necrosis factor (TNF)related apoptosis-inducing ligand (TRAIL) and was based on albumin, demonstrating synergistic anti-tumor efficacy, and providing a new inhalation-based combination therapies to treat drug-resistant lung cancer with the obvious reduction of the dose of doxorubicin (119). Currently, the most extensively used albumin nanoparticles is nab-paclitaxel (Abraxane ${ }^{\mathrm{TM}}$ ), which approved for the treatment of breast cancer, metastatic non-small cell lung cancer (NSCLC) and pancreatic cancer. Besides, there are still many clinical trials based on the combination of nab-paclitaxel and other drugs (such as cisplatin, oxaliplatin, toripalimab, and S1) to obtain better therapeutic effect through combination therapy.

Polyethylene glycol (PEG) is the chief ingredient used to synthesize nanoparticles and modify the surface of nanomaterials. PEG-b-PLA micelles are the first-generation platform with a hydrodynamic diameter of $33 \mathrm{~nm}$ in the usage of systemic multiple administration of poorly water-soluble anti-cancer agents (123). The combination of PEG-b-PLA micelles with paclitaxel $\left(\right.$ Genexol-PM ${ }^{\circledR}$ ) has been used in clinical cancer treatment with a high response rate in clinical trials in patients with NSCLC, gastric cancer, breast cancer and fewer acute hypersensitivity reactions (123).

Cyclodextrins (CDs) and other polymers were often combined with water-insoluble pharmaceutical drugs to increase their solubility and availability (124). Cyclodextrins- camptothecin (CRLX101) complex optimized the plasma pharmacokinetics and then facilitated drug delivery to tumors (125). The preferential uptake of cyclodextrins and camptothecin conjugation may promote the selective release of tumor antigens into TME and enhance the effect of tumor immune drugs (126). Preclinical studies have proven that CRLX101 could reduce adverse reactions and increase NK cell and T cell populations, which may potentially improve the anti-PD1/PDL1 therapy (127).

Cholesteryl pullulan (CHP) nanogel is a novel antigen delivery system based on CHP nanogel that has been accomplished phase I clinical trials. CHP is conjugated to HER2 and NY-ESO-1 antigenrelated cancer vaccine. Additionally, HP-NY-ESO-1 is a safe and promising cancer vaccine. In previous studies, CHP-NY-ESO-1 vaccination showed $\mathrm{CD}^{+}$and $\mathrm{CD}^{+} \mathrm{T}$ cell response activities (128). The addition of anti-PD-1 activates NY-ESO-1 specific T cells as well as other tumor antigen-reactive T cells. Afterwards, clinical trials of combined therapies including cancer vaccines, adjuvants and ICBs, are ready to proceed (129). Comparatively, the CHP-HER2 vaccine is well tolerated, and HER2-specific CD ${ }^{+}$ and $\mathrm{CD} 4^{+} \mathrm{T}$ cell immune responses have been detected in patients who had received the vaccine (109).

Autophagy in tumor cells also plays a key role in the crosspresentation of tumor antigens (130). Tumor-derived autophagasomes vaccine named DRibbles is defined as a novel type of multivalent vaccine which was produced by disrupting the ubiquitin proteasome system to degrade intracellular proteins. DRibbles vaccine consists of autophagic vesicles which are rich in defective ribosomal products and short-lived proteins, known tumor-associated antigens, mediators of innate immunity and surface markers that promote phagocytosis and cross-presentation of antigen-presenting cells (131). Human antigen-specific memory $\mathrm{T}$ cells can be activated by specific viral antigens during immune monitoring and adoptive immunotherapy. As a result, Dribbles vaccine will be a vaccine for cancer patients in the future (132). In the phase I of clinical trials, DRibbles had been derived from autologous tumor cells and applied to vaccinate patients with NSCLC, following a randomized multi-center phase II clinical trial was initiated to use allogeneic DRibbles vaccine (132). The available evidence supported that DRibbles vaccine is a human treatment strategy in the latest clinical development and it promises to be a delivery mechanism for other vaccines in the future.

Virus-like particles (VLPs) are nanoparticles that selfassembled by one or more viral proteins, with the diameter of about 10-200nm (133). VLPs do not contain nuclei acids which exhibit non-infectious function for the vaccinated individuals. By contrast, the structure of VLPs are similar to the conformation of wild type viruses which can activate adaptive immunity (134). VLPs can be modified by chemical or genetic fusion technologies to express chimeras or targeted delivery of small molecule drugs and nucleic acids as a result of the improvement of bioavailability of the delivered substance (135). Thus, VLPs can restore immune response, cross-present and induce CTL responses. Furthermore, VLPs identify and combine specific pattern recognition receptors on the surface of DCs followed by internalizing into activate DCs, and then present peptides which was loaded into MHC-I/II. Eventually, they in turn initiate $\mathrm{CD} 8^{+}$or $\mathrm{CD} 4^{+} \mathrm{T}$ cell immunity (134). Collectively, the ability to engineer VLPs with exquisite detail makes them popular candidates for the design of a platform to produce vaccines against various diseases.

\section{APPLICATION PROSPECTS OF NANOMEDICINE IN IMMUNOTHERAPY}

Immunotherapy has become a vital tool of cancer treatment. The effectiveness of immunotherapy is various in tumor subtypes. The development mechanism of primary tumors and immune regulation mechanisms have been the key to clarify the difference in efficacy of 


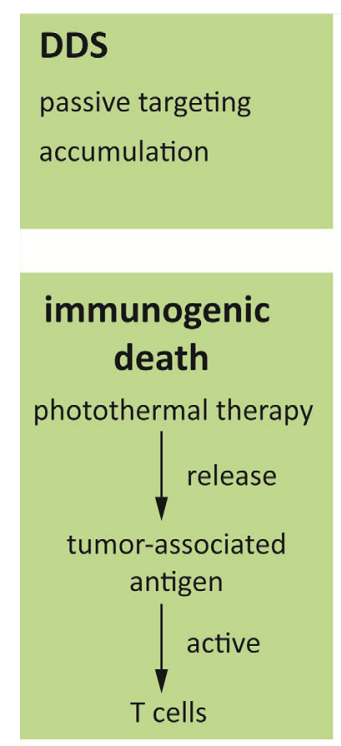

TME

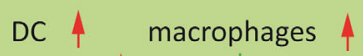

T cells 4 Tregs

vaccine adjuvant

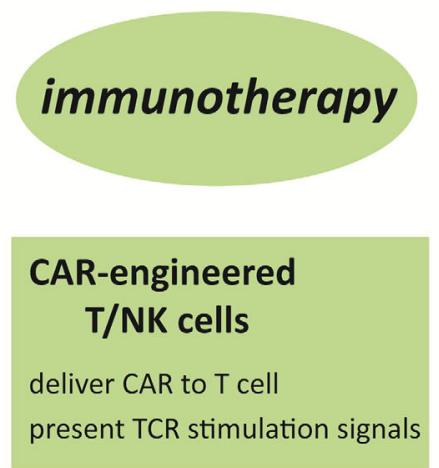

\section{nano-antibody}

nanobiosensor

active targeting

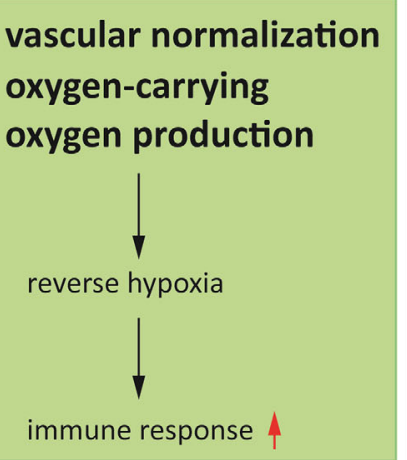

FIGURE 5 | Mechanism of nanoparticles in immunotherapy.

immunotherapy. Even so, the hurdles existed in conventional tumor immunotherapy hindered the progress of tumor immunotherapy. With the advancement of nanotechnology, the use of nanomaterials should not be ignored in tumor therapy due to their intrinsic immune modulation activities. The auxiliary applications of nanomaterials will provide a predictable guarantee for the effectiveness and safety of immune interventions (Figure 5). Nanomedicines take advantages of immunotherapies in four aspects. 1) Immunomodulators, such as immunopharmaceuticals, vaccines, siRNAs, etc. carried by nanomaterials can be slowly released on specific targets to prolong the effect of immunotherapy and reduce systemic side effects. 2) The photothermal effect mediated by nanomaterials triggers immunogenic cell death. 3) The modified nanomaterials can activate cytotoxic $\mathrm{T}$ cells and antigen-presenting cells, reverse the polarization of macrophages and inhibit Treg cells, thereby enhancing the tumor killing effect. 4) Regulating tumor blood vessels and tumor hypoxic microenvironment not only enhances the sensitivity of immunotherapy, but also strengthens the therapeutic effect of radiotherapy and chemotherapy. In summary, nanomedicine has extremely high variability in material and particle size selection, surface modification, packaged drug selection, and drug delivery schemes. Therefore, there is extensive optimization space for nanomedicine to improve. In the past decades, the practicality of biomaterials has been verified in the field of tumor therapy. Afterwards, more than ten kinds of nanobased drugs have been approved for tumor or other diseases clinical treatment. And now, the clinical transformation of material-based cancer immunotherapy is accelerating. In the future, the principles

\section{REFERENCES}

1. Luo L, Iqbal MZ, Liu C, Xing J, Akakuru OU, Fang Q, et al. Engineered nano-immunopotentiators efficiently promote cancer immunotherapy for we have learned from the existing experience of using nanomaterials will guide us to design more effective cancer immunotherapies, allowing for extend the frontiers of more successful cancer treatment.

\section{AUTHOR CONTRIBUTIONS}

WL wrote the majority of the manuscript. AP cowrote the manuscript. HW and YQ drew images and summarized tables. YL supervised the research. LL and MC designed and cowrote the manuscript, and supervised the research. All authors contributed to the article and approved the submitted version.

\section{FUNDING}

This work is partially supported by National Key Research and Development Program of China (No. 2017YFA0205200) and the National Natural Science Foundation of China (No. 81571785, 81771957, 81801811).

\section{SUPPLEMENTARY MATERIAL}

The Supplementary Material for this article can be found online at: https://www.frontiersin.org/articles/10.3389/fimmu.2020. 601497/full\#supplementary-material

inhibiting and preventing lung metastasis of melanoma. Biomaterials (2019) 223:119464. doi: 10.1016/j.biomaterials.2019.119464

2. Schmid P, Adams S, Rugo HS, Schneeweiss A, Barrios $\mathrm{CH}$, Iwata $\mathrm{H}$, et al. Atezolizumab and Nab-Paclitaxel in Advanced Triple-Negative Breast 
Cancer. N Engl J Medicine (2018) 379(22):2108-21. doi: 10.1056/ NEJMoa1809615

3. Ma Y, Zhang Y, Li X, Zhao Y, Li M, Jiang W, et al. Near-Infrared II Phototherapy Induces Deep Tissue Immunogenic Cell Death and Potentiates Cancer Immunotherapy. ACS Nano (2019) 13(10):11967-80. doi: $10.1021 / a c s n a n o .9 b 06040$

4. Zhang R, Zhu Z, Lv H, Li F, Sun S, Li J, et al. Immune Checkpoint Blockade Mediated by a Small-Molecule Nanoinhibitor Targeting the PD-1/PD-L1 Pathway Synergizes with Photodynamic Therapy to Elicit Antitumor Immunity and Antimetastatic Effects on Breast Cancer. Small (2019) 15 (49):e1903881. doi: 10.1002/smll.201903881

5. Friedman J, Moore EC, Zolkind P, Robbins Y, Clavijo PE, Sun L, et al. Neoadjuvant PD-1 Immune Checkpoint Blockade Reverses Functional Immunodominance among Tumor Antigen-Specific T Cells. Clin Cancer Res (2020) 26(3):679-89. doi: 10.1158/1078-0432.CCR-19-2209

6. Sussman JJ, Shu S, Sondak VK, Chang AE. Activation of T lymphocytes for the adoptive immunotherapy of cancer. Ann Surg Oncol (1994) 1(4):296306. doi: 10.1007/bf02303568

7. Hodi FS, Chiarion-Sileni V, Gonzalez R, Grob JJ, Rutkowski P, Cowey CL, et al. Nivolumab plus ipilimumab or nivolumab alone versus ipilimumab alone in advanced melanoma (CheckMate 067): 4-year outcomes of a multicentre, randomised, phase 3 trial. Lancet Oncol (2018) 19(11):148092. doi: 10.1016/S1470-2045(18)30700-9

8. Hargadon KM, Johnson CE, Williams CJ. Immune checkpoint blockade therapy for cancer: An overview of FDA-approved immune checkpoint inhibitors. Int Immunopharmacol (2018) 62:29-39. doi: 10.1016/j.intimp. 2018.06.001

9. Skoulidis F, Goldberg ME, Greenawalt DM, Hellmann MD, Awad MM, Gainor JF, et al. STK11/LKB1 Mutations and PD-1 Inhibitor Resistance in KRAS-Mutant Lung Adenocarcinoma. Cancer Discov (2018) 8(7):822-35. doi: 10.1158/2159-8290.CD-18-0099

10. O'Donnell JS, Teng MWL, Smyth MJ. Cancer immunoediting and resistance to T cell-based immunotherapy. Nat Rev Clin Oncol (2019) 16(3):151-67. doi: 10.1038/s41571-018-0142-8

11. Yau T, Hsu C, Kim TY, Choo SP, Kang YK, Hou MM, et al. Nivolumab in advanced hepatocellular carcinoma: Sorafenib-experienced Asian cohort analysis. J Hepatol (2019) 71(3):543-52. doi: 10.1016/j.jhep.2019.05.014

12. Horn L, Mansfield AS, Szczesna A, Havel L, Krzakowski M, Hochmair MJ, et al. First-Line Atezolizumab plus Chemotherapy in Extensive-Stage SmallCell Lung Cancer. N Engl J Med (2018) 379(23):2220-9. doi: 10.1056/ NEJMoa1 809064

13. Finn RS, Ryoo BY, Merle P, Kudo M, Bouattour M, Lim HY, et al. Pembrolizumab As Second-Line Therapy in Patients With Advanced Hepatocellular Carcinoma in KEYNOTE-240: A Randomized, DoubleBlind, Phase III Trial. J Clin Oncol (2020) 38(3):193-202. doi: 10.1200/ JCO.19.01307

14. Sanmamed MF, Chen L. A Paradigm Shift in Cancer Immunotherapy: From Enhancement to Normalization. Cell (2019) 176(3):677. doi: 10.1016/ j.cell.2019.01.008

15. Schachter J, Ribas A, Long GV, Arance A, Grob JJ, Mortier L, et al. Pembrolizumab versus ipilimumab for advanced melanoma: final overall survival results of a multicentre, randomised, open-label phase 3 study (KEYNOTE-006). Lancet (2017) 390(10105):1853-62. doi: 10.1016/S01406736(17)31601-X

16. McQuade JL, Homsi J, Torres-Cabala CA, Bassett R, Popuri RM, James ML, et al. A phase II trial of recombinant MAGE-A3 protein with immunostimulant AS15 in combination with high-dose Interleukin-2 (HDIL2) induction therapy in metastatic melanoma. BMC Cancer (2018) 18(1):1274. doi: 10.1186/s12885-018-5193-9

17. Larkin J, Chiarion-Sileni V, Gonzalez R, Grob JJ, Cowey CL, Lao CD, et al. Combined Nivolumab and Ipilimumab or Monotherapy in Untreated Melanoma. N Engl J Med (2015) 373(1):23-34. doi: 10.1056/ NEJMoa 1504030

18. Larkin J, Chiarion-Sileni V, Gonzalez R, Grob JJ, Rutkowski P, Lao CD, et al. Five-Year Survival with Combined Nivolumab and Ipilimumab in Advanced Melanoma. N Engl J Med (2019) 381(16):1535-46. doi: 10.1056/ NEJMoa1910836
19. Hellmann MD, Paz-Ares L, Bernabe Caro R, Zurawski B, Kim SW, Carcereny Costa E, et al. Nivolumab plus Ipilimumab in Advanced NonSmall-Cell Lung Cancer. N Engl J Med (2019) 381(21):2020-31. doi: 10.1056/NEJMoa1910231

20. Motzer RJ, Tannir NM, McDermott DF, Aren Frontera O, Melichar B, Choueiri TK, et al. Nivolumab plus Ipilimumab versus Sunitinib in Advanced Renal-Cell Carcinoma. N Engl J Med (2018) 378(14):1277-90. doi: 10.1056/NEJMoa1712126

21. Hodi FS, Lawrence D, Lezcano C, Wu X, Zhou J, Sasada T, et al. Bevacizumab plus ipilimumab in patients with metastatic melanoma. Cancer Immunol Res (2014) 2(7):632-42. doi: 10.1158/2326-6066.CIR-140053

22. Apetoh L, Ladoire S, Coukos G, Ghiringhelli F. Combining immunotherapy and anticancer agents: the right path to achieve cancer cure? Ann Oncol (2015) 26(9):1813-23. doi: 10.1093/annonc/mdv209

23. Voorwerk L, Slagter M, Horlings HM, Sikorska K, van de Vijver KK, de Maaker $\mathrm{M}$, et al. Immune induction strategies in metastatic triple-negative breast cancer to enhance the sensitivity to PD-1 blockade: the TONIC trial. Nat Med (2019) 25(6):920-8. doi: 10.1038/s41591-019-0432-4

24. Langer CJ, Gadgeel SM, Borghaei H, Papadimitrakopoulou VA, Patnaik A, Powell SF, et al. Carboplatin and pemetrexed with or without pembrolizumab for advanced, non-squamous non-small-cell lung cancer: a randomised, phase 2 cohort of the open-label KEYNOTE-021 study. Lancet Oncol (2016) 17(11):1497-508. doi: 10.1016/S1470-2045(16)30498-3

25. Zhang P, Ma Y, Lv C, Huang M, Li M, Dong B, et al. Upregulation of programmed cell death ligand 1 promotes resistance response in non-smallcell lung cancer patients treated with neo-adjuvant chemotherapy. Cancer Sci (2016) 107(11):1563-71. doi: 10.1111/cas.13072

26. Gilad Y, Eliaz Y, Yu Y, Han SJ, O’Malley BW, Lonard DM. Drug-induced PD-L1 expression and cell stress response in breast cancer cells can be balanced by drug combination. Sci Rep (2019) 9(1):15099. doi: 10.1038/ s41598-019-51537-7

27. Bozorgmehr F, Hommertgen A, Krisam J, Lasitschka F, Kuon J, Maenz M, et al. Fostering efficacy of anti-PD-1-treatment: Nivolumab plus radiotherapy in advanced non-small cell lung cancer - study protocol of the FORCE trial. BMC Cancer (2019) 19(1):1074. doi: 10.1186/s12885-019$6205-0$

28. Qin Q, Nan X, Miller T, Fisher R, Teh B, Pandita S, et al. Complete Local and Abscopal Responses from a Combination of Radiation and Nivolumab in Refractory Hodgkin's Lymphoma. Radiat Res (2018) 190(3):322-9. doi: 10.1667/RR15048.1

29. Hughes PE, Caenepeel S, Wu LC. Targeted Therapy and Checkpoint Immunotherapy Combinations for the Treatment of Cancer. Trends Immunol (2016) 37(7):462-76. doi: 10.1016/j.it.2016.04.010

30. Ascierto PA, Ferrucci PF, Fisher R, Del Vecchio M, Atkinson V, Schmidt H, et al. Dabrafenib, trametinib and pembrolizumab or placebo in BRAFmutant melanoma. Nat Med (2019) 25(6):941-6. doi: 10.1038/s41591-019$0448-9$

31. Ribas A, Lawrence D, Atkinson V, Agarwal S, Miller WHJr., Carlino MS, et al. and MEK inhibition with PD-1 blockade immunotherapy in BRAFmutant melanoma. Nat Med (2019) 25(6):936-40. doi: 10.1038/s41591-0190476-5

32. Pauken KE, Dougan M, Rose NR, Lichtman AH, Sharpe AH. Adverse Events Following Cancer Immunotherapy: Obstacles and Opportunities. Trends Immunol (2019) 40(6):511-23. doi: 10.1016/j.it.2019.04.002

33. Rapoport BL, van Eeden R, Sibaud V, Epstein JB, Klastersky J, Aapro M, et al. Supportive care for patients undergoing immunotherapy. Support Care Cancer Off J Multinational Assoc Support Care Cancer (2017) 25(10):301730. doi: 10.1007/s00520-017-3802-9

34. Ishihara J, Ishihara A, Sasaki K, Lee SS, Williford JM, Yasui M, et al. Targeted antibody and cytokine cancer immunotherapies through collagen affinity. Sci Trans Med (2019) 11(487):eaau3259. doi: 10.1126/scitranslmed.aau3259

35. Winer A, Bodor JN, Borghaei H. Identifying and managing the adverse effects of immune checkpoint blockade. J Thoracic Dis (2018) 10(Suppl 3): S480-9. doi: 10.21037/jtd.2018.01.111

36. Spain L, Diem S, Larkin J. Management of toxicities of immune checkpoint inhibitors. Cancer Treat Rev (2016) 44:51-60. doi: 10.1016/j.ctrv.2016.02.001 
37. Postow MA, Chesney J, Pavlick AC, Robert C, Grossmann K, McDermott D, et al. Nivolumab and ipilimumab versus ipilimumab in untreated melanoma. N Engl J Med (2015) 372(21):2006-17. doi: 10.1056/NEJMoa1414428

38. Zhang B, Wu Q, Zhou YL, Guo X, Ge J, Fu J. Immune-related adverse events from combination immunotherapy in cancer patients: A comprehensive meta-analysis of randomized controlled trials. Int Immunopharmacol (2018) 63:292-8. doi: 10.1016/j.intimp.2018.08.014

39. Riley RS, June CH, Langer R, Mitchell MJ. Delivery technologies for cancer immunotherapy. Nat Rev Drug Discov (2019) 18(3):175-96. doi: 10.1038/ s41573-018-0006-Z

40. Zhu G, Lynn GM, Jacobson O, Chen K, Liu Y, Zhang H, et al. Albumin/ vaccine nanocomplexes that assemble in vivo for combination cancer immunotherapy. Nat Commun (2017) 8(1):1954. doi: 10.1038/s41467-01702191-y

41. Ordikhani F, Uehara M, Kasinath V, Dai L, Eskandari SK, Bahmani B, et al. Targeting antigen-presenting cells by anti-PD-1 nanoparticles augments antitumor immunity. JCI Insight (2018) 3(20):e122700. doi: 10.1172/ jci.insight. 122700

42. Hei Y, Teng B, Zeng Z, Zhang S, Li Q, Pan J, et al. Multifunctional Immunoliposomes Combining Catalase and PD-L1 Antibodies Overcome Tumor Hypoxia and Enhance Immunotherapeutic Effects Against Melanoma. Int J Nanomed (2020) 15:1677-91. doi: 10.2147/IJN.S225807

43. Qian Y, Qiao S, Dai Y, Xu G, Dai B, Lu L, et al. Molecular-Targeted Immunotherapeutic Strategy for Melanoma via Dual-Targeting Nanoparticles Delivering Small Interfering RNA to Tumor-Associated Macrophages. ACS Nano (2017) 11(9):9536-49. doi: 10.1021/ acsnano.7b05465

44. Teo PY, Yang C, Whilding LM, Parente-Pereira AC, Maher J, George AJ, et al. Ovarian cancer immunotherapy using PD-L1 siRNA targeted delivery from folic acid-functionalized polyethylenimine: strategies to enhance $\mathrm{T}$ cell killing. Adv Healthcare Mater (2015) 4(8):1180-9. doi: 10.1002/ adhm.201500089

45. Song W, Shen L, Wang Y, Liu Q, Goodwin TJ, Li J, et al. Synergistic and low adverse effect cancer immunotherapy by immunogenic chemotherapy and locally expressed PD-L1 trap. Nat Commun (2018) 9(1):2237. doi: 10.1038/ s41467-018-04605-x

46. Graham K, Unger E. Overcoming tumor hypoxia as a barrier to radiotherapy, chemotherapy and immunotherapy in cancer treatment. Int J Nanomed (2018) 13:6049-58. doi: 10.2147/IJN.S140462

47. Jahanban-Esfahlan R, de la Guardia M, Ahmadi D, Yousefi B. Modulating tumor hypoxia by nanomedicine for effective cancer therapy. J Cell Physiol (2018) 233(3):2019-31. doi: 10.1002/jcp.25859

48. Jayaprakash P, Ai M, Liu A, Budhani P, Bartkowiak T, Sheng J, et al. Targeted hypoxia reduction restores $\mathrm{T}$ cell infiltration and sensitizes prostate cancer to immunotherapy. J Clin Invest (2018) 128(11):5137-49. doi: 10.1172/JCI96268

49. Daniel SK, Sullivan KM, Labadie KP, Pillarisetty VG. Hypoxia as a barrier to immunotherapy in pancreatic adenocarcinoma. Clin Trans Med (2019) 8 (1):10. doi: 10.1186/s40169-019-0226-9

50. Noman MZ, Hasmim M, Lequeux A, Xiao M, Duhem C, Chouaib S, et al. Improving Cancer Immunotherapy by Targeting the Hypoxic Tumor Microenvironment: New Opportunities and Challenges. Cells (2019) 8 (9):1083. doi: 10.3390/cells8091083

51. Chouaib S, Messai Y, Couve S, Escudier B, Hasmim M, Noman MZ. Hypoxia promotes tumor growth in linking angiogenesis to immune escape. Front Immunol (2012) 3:21. doi: 10.3389/fimmu.2012.00021

52. Palazon A, Aragones J, Morales-Kastresana A, de Landazuri MO, Melero I. Molecular pathways: hypoxia response in immune cells fighting or promoting cancer. Clin Cancer Res (2012) 18(5):1207-13. doi: 10.1158/ 1078-0432.CCR-11-1591

53. Wang H, Li J, Wang Y, Gong X, Xu X, Wang J, et al. Nanoparticles-mediated reoxygenation strategy relieves tumor hypoxia for enhanced cancer therapy. J Controlled Release (2020) 319:25-45. doi: 10.1016/j.jconrel.2019.12.028

54. Chung CH, Lu KY, Lee WC, Hsu WJ, Lee WF, Dai JZ, et al. Fucoidan-based, tumor-activated nanoplatform for overcoming hypoxia and enhancing photodynamic therapy and antitumor immunity. Biomaterials (2020) 257:120227. doi: 10.1016/j.biomaterials.2020.120227
55. Chen Q, Xu L, Chen J, Yang Z, Liang C, Yang Y, et al. Tumor vasculature normalization by orally fed erlotinib to modulate the tumor microenvironment for enhanced cancer nanomedicine and immunotherapy. Biomaterials (2017) 148:69-80. doi: 10.1016/ j.biomaterials.2017.09.021

56. Sung YC, Jin PR, Chu LA, Hsu FF, Wang MR, Chang CC, et al. Delivery of nitric oxide with a nanocarrier promotes tumour vessel normalization and potentiates anti-cancer therapies. Nat Nanotechnol (2019) 14(12):1160-9. doi: 10.1038/s41565-019-0570-3

57. Mpekris F, Voutouri C, Baish JW, Duda DG, Munn LL, Stylianopoulos T, et al. Combining microenvironment normalization strategies to improve cancer immunotherapy. Proc Natl Acad Sci U S A (2020) 117(7):3728-37. doi: 10.1073/pnas.1919764117

58. Li W, Li X, Liu S, Yang W, Pan F, Yang XY, et al. Gold nanoparticles attenuate metastasis by tumor vasculature normalization and epithelialmesenchymal transition inhibition. Int J Nanomed (2017) 12:3509-20. doi: $10.2147 /$ IJN.S128802

59. Gurunathan S, Lee KJ, Kalishwaralal K, Sheikpranbabu S, Vaidyanathan R, Eom SH. Antiangiogenic properties of silver nanoparticles. Biomaterials (2009) 30(31):6341-50. doi: 10.1016/j.biomaterials.2009.08.008

60. Taleb M, Ding Y, Wang B, Yang N, Han X, Du C, et al. Dopamine Delivery via $\mathrm{pH}$-Sensitive Nanoparticles for Tumor Blood Vessel Normalization and an Improved Effect of Cancer Chemotherapeutic Drugs. Adv Healthcare Mater (2019) 8(18):e1900283. doi: 10.1002/adhm.201900283

61. Wang B, Ding Y, Zhao X, Han X, Yang N, Zhang Y, et al. Delivery of small interfering RNA against Nogo-B receptor via tumor-acidity responsive nanoparticles for tumor vessel normalization and metastasis suppression. Biomaterials (2018) 175:110-22. doi: 10.1016/j.biomaterials.2018.05.034

62. Zheng D, Li B, Xu L, Zhang QL, Fan JX, Li CX, et al. Normalizing Tumor Microenvironment Based on Photosynthetic Abiotic/Biotic Nanoparticles. ACS Nano (2018) 12(6):6218-27. doi: 10.1021/acsnano.8b02977

63. Ruscetti M, Morris J, Mezzadra R, Russell J, Leibold J, Romesser PB, et al. Senescence-Induced Vascular Remodeling Creates Therapeutic Vulnerabilities in Pancreas Cancer. Cell (2020) 181(2):424-41.e21. doi: 10.1016/j.cell.2020.03.008

64. He B, Johansson-Percival A, Backhouse J, Li J, Lee GYF, Hamzah J, et al. Remodeling of Metastatic Vasculature Reduces Lung Colonization and Sensitizes Overt Metastases to Immunotherapy. Cell Rep (2020) 30(3):71424.e5. doi: 10.1016/j.celrep.2019.12.013

65. Hu D, Chen L, Qu Y, Peng J, Chu B, Shi K, et al. Oxygen-generating Hybrid Polymeric Nanoparticles with Encapsulated Doxorubicin and Chlorin e6 for Trimodal Imaging-Guided Combined Chemo-Photodynamic Therapy. Theranostics (2018) 8(6):1558-74. doi: 10.7150/thno.22989

66. Meng L, Cheng Y, Tong X, Gan S, Ding Y, Zhang Y, et al. Tumor Oxygenation and Hypoxia Inducible Factor-1 Functional Inhibition via a Reactive Oxygen Species Responsive Nanoplatform for Enhancing Radiation Therapy and Abscopal Effects. ACS Nano (2018) 12(8):8308-22. doi: 10.1021/acsnano.8b03590

67. Chen H, Ma A, Yin T, Chen Z, Liang R, Pan H, et al. In Situ Photocatalysis of TiO-Porphyrin-Encapsulated Nanosystem for Highly Efficient Oxidative Damage against Hypoxic Tumors. ACS Appl Mater Interf (2020) 12 (11):12573-83. doi: 10.1021/acsami.0c00921

68. Zhang Z, Niu N, Gao X, Han F, Chen Z, Li S, et al. A new drug carrier with oxygen generation function for modulating tumor hypoxia microenvironment in cancer chemotherapy. Colloids Surfaces B Biointerf (2019) 173:335-45. doi: 10.1016/j.colsurfb.2018.10.008

69. Zhou Z, Zhang B, Wang H, Yuan A, Hu Y, Wu J. Two-stage oxygen delivery for enhanced radiotherapy by perfluorocarbon nanoparticles. Theranostics (2018) 8(18):4898-911. doi: 10.7150/thno.27598

70. Ma S, Zhou J, Zhang Y, Yang B, He Y, Tian C, et al. An Oxygen Self-sufficient Fluorinated Nanoplatform for Relieved Tumor Hypoxia and Enhanced Photodynamic Therapy of Cancers. ACS Appl Mater Interf (2019) 11 (8):7731-42. doi: 10.1021/acsami.8b19840

71. Zhou Z, Zhang B, Wang S, Zai W, Yuan A, Hu Y, et al. Perfluorocarbon Nanoparticles Mediated Platelet Blocking Disrupt Vascular Barriers to Improve the Efficacy of Oxygen-Sensitive Antitumor Drugs. Small (2018) 14(45):e1801694. doi: 10.1002/smll.201801694 
72. Chen L, Wang Z, Xu Q, Liu Y, Chen L, Guo S, et al. The failure of DAC to induce OCT2 expression and its remission by hemoglobin-based nanocarriers under hypoxia in renal cell carcinoma. Theranostics (2020) 10(8):3562-78. doi: 10.7150/thno.39944

73. Chen Q, Hu Q, Dukhovlinova E, Chen G, Ahn S, Wang C, et al. Photothermal Therapy Promotes Tumor Infiltration and Antitumor Activity of CAR T Cells. Adv Mater (2019) 31(23):e1900192. doi: 10.1002/ adma.201900192

74. Stern JM, Kibanov Solomonov VV, Sazykina E, Schwartz JA, Gad SC, Goodrich GP. Initial Evaluation of the Safety of Nanoshell-Directed Photothermal Therapy in the Treatment of Prostate Disease. Int $J$ Toxicol (2016) 35(1):38-46. doi: 10.1177/1091581815600170

75. Liu C, Luo L, Zeng L, Xing J, Xia Y, Sun S, et al. Porous Gold Nanoshells on Functional NH2 -MOFs: Facile Synthesis and Designable Platforms for Cancer Multiple Therapy. Small (2018) 14(35):e1801851. doi: 10.1002/ smll. 201801851

76. Liu Y, Crawford BM, Vo-Dinh T. Gold nanoparticles-mediated photothermal therapy and immunotherapy. Immunotherapy (2018) 10 (13):1175-88. doi: 10.2217/imt-2018-0029

77. Chen W, Qin M, Chen X, Wang Q, Zhang Z, Sun X. Combining photothermal therapy and immunotherapy against melanoma by polydopamine-coated Al2O3 nanoparticles. Theranostics (2018) 8 (8):2229-41. doi: 10.7150/thno.24073

78. Peng J, Xiao Y, Li W, Yang Q, Tan L, Jia Y, et al. Photosensitizer Micelles Together with IDO Inhibitor Enhance Cancer Photothermal Therapy and Immunotherapy. Adv Sci (2018) 5(5):1700891. doi: 10.1002/advs. 201700891

79. Chiang CS, Lin YJ, Lee R, Lai YH, Cheng HW, Hsieh CH, et al. Combination of fucoidan-based magnetic nanoparticles and immunomodulators enhances tumour-localized immunotherapy. Nat Nanotechnol (2018) 13(8):746-54. doi: 10.1038/s41565-018-0146-7

80. Mi Y, Smith CC, Yang F, Qi Y, Roche KC, Serody JS, et al. Dual Immunotherapy Nanoparticle Improves T-Cell Activation and Cancer Immunotherapy. Adv Mater (2018) 30(25):e1706098. doi: 10.1002/ adma.201706098

81. Zheng S, Qin T, Lu Y, Huang Y, Luo L, Liu Z, et al. Maturation of dendritic cells in vitro and immunological enhancement of mice in vivo by pachymanand/or OVA-encapsulated poly(d,l-lactic acid) nanospheres. Int J Nanomed (2018) 13:569-83. doi: 10.2147/IJN.S153567

82. Dong H, Wen ZF, Chen L, Zhou N, Liu H, Dong S, et al. Polyethyleneimine modification of aluminum hydroxide nanoparticle enhances antigen transportation and cross-presentation of dendritic cells. Int $J$ Nanomed (2018) 13:3353-65. doi: 10.2147/IJN.S164097

83. Tu K, Deng H, Kong L, Wang Y, Yang T, Hu Q, et al. Reshaping Tumor Immune Microenvironment through Acidity-Responsive Nanoparticles Featured with CRISPR/Cas9-Mediated Programmed Death-Ligand 1 Attenuation and Chemotherapeutics-Induced Immunogenic Cell Death. ACS Appl Mater Interf (2020) 12(14):16018-30. doi: 10.1021/acsami. $9 \mathrm{~b} 23084$

84. Korangath P, Barnett JD, Sharma A, Henderson ET, Stewart J, Yu SH, et al. Nanoparticle interactions with immune cells dominate tumor retention and induce T cell-mediated tumor suppression in models of breast cancer. Sci $A d v$ (2020) 6(13):eaay1601. doi: 10.1126/sciadv.aay1601

85. Deng RH, Zou MZ, Zheng D, Peng SY, Liu W, Bai XF, et al. Nanoparticles from Cuttlefish Ink Inhibit Tumor Growth by Synergizing Immunotherapy and Photothermal Therapy. ACS Nano (2019) 13(8):8618-29. doi: 10.1021/ acsnano.9b02993

86. Liu H, Moynihan KD, Zheng Y, Szeto GL, Li AV, Huang B, et al. Structurebased programming of lymph-node targeting in molecular vaccines. Nature (2014) 507(7493):519-22. doi: 10.1038/nature12978

87. Jeanbart L, Ballester M, de Titta A, Corthesy P, Romero P, Hubbell JA, et al. Enhancing efficacy of anticancer vaccines by targeted delivery to tumordraining lymph nodes. Cancer Immunol Res (2014) 2(5):436-47. doi: 10.1158/2326-6066.CIR-14-0019-T

88. Bo R, Sun Y, Zhou S, Ou N, Gu P, Liu Z, et al. Simple nanoliposomes encapsulating Lycium barbarum polysaccharides as adjuvants improve humoral and cellular immunity in mice. Int J Nanomed (2017) 12:6289301. doi: $10.2147 / \mathrm{IJN} . S 136820$
89. Haughney SL, Ross KA, Boggiatto PM, Wannemuehler MJ, Narasimhan B. Effect of nanovaccine chemistry on humoral immune response kinetics and maturation. Nanoscale (2014) 6(22):13770-8. doi: 10.1039/c4nr03724c

90. Billingsley MM, Singh N, Ravikumar P, Zhang R, June CH, Mitchell MJ. Ionizable Lipid Nanoparticle-Mediated mRNA Delivery for Human CAR T Cell Engineering. Nano Lett (2020) 20(3):1578-89. doi: 10.1021/ acs.nanolett.9b04246

91. Nawaz W, Xu S, Li Y, Huang B, Wu X, Wu Z. Nanotechnology and immunoengineering: How nanotechnology can boost CAR-T therapy. Acta Biomater (2020) 109:21-36. doi: 10.1016/j.actbio.2020.04.015

92. Dunn ZS, Mac J, Wang P. T cell immunotherapy enhanced by designer biomaterials. Biomaterials (2019) 217:119265. doi: 10.1016/j.biomaterials. 2019.119265

93. Yu Q, Zhang M, Chen Y, Chen X, Shi S, Sun K, et al. Self-Assembled Nanoparticles Prepared from Low-Molecular-Weight PEI and LowGeneration PAMAM for EGFRvIII-Chimeric Antigen Receptor Gene Loading and T-Cell Transient Modification. Int J Nanomed (2020) 15:483-95. doi: 10.2147/IJN.S229858

94. Siriwon N, Kim YJ, Siegler E, Chen X, Rohrs JA, Liu Y, et al. CAR-T Cells Surface-Engineered with Drug-Encapsulated Nanoparticles Can Ameliorate Intratumoral T-cell Hypofunction. Cancer Immunol Res (2018) 6(7):812-24. doi: 10.1158/2326-6066.CIR-17-0502

95. Kim GB, Aragon-Sanabria V, Randolph L, Jiang H, Reynolds JA, Webb BS, et al. High-affinity mutant Interleukin-13 targeted CAR T cells enhance delivery of clickable biodegradable fluorescent nanoparticles to glioblastoma. Bioactive Mater (2020) 5(3):624-35. doi: 10.1016/j.bioactmat.2020.04.011

96. Moffett HF, Coon ME, Radtke S, Stephan SB, McKnight L, Lambert A, et al. Hit-and-run programming of therapeutic cytoreagents using mRNA nanocarriers. Nat Commun (2017) 8(1):389. doi: 10.1038/s41467-01700505-8

97. Zheng Y, Stephan MT, Gai SA, Abraham W, Shearer A, Irvine DJ. In vivo targeting of adoptively transferred T-cells with antibody- and cytokineconjugated liposomes. J Controlled Release (2013) 172(2):426-35. doi: 10.1016/j.jconrel.2013.05.037

98. Perica K, Bieler JG, Schutz C, Varela JC, Douglass J, Skora A, et al. Enrichment and Expansion with Nanoscale Artificial Antigen Presenting Cells for Adoptive Immunotherapy. ACS Nano (2015) 9(7):6861-71. doi: 10.1021/acsnano.5b02829

99. Bai C, Gao S, Hu S, Liu X, Li H, Dong J, et al. Self-Assembled Multivalent Aptamer Nanoparticles with Potential CAR-like Characteristics Could Activate T Cells and Inhibit Melanoma Growth. Mol Ther Oncolytics (2020) 17:9-20. doi: 10.1016/j.omto.2020.03.002

100. Matosevic S. Viral and Nonviral Engineering of Natural Killer Cells as Emerging Adoptive Cancer Immunotherapies. J Immunol Res (2018) 2018:4054815. doi: 10.1155/2018/4054815

101. Nakamura T, Kuroi M, Fujiwara Y, Warashina S, Sato Y, Harashima H. Small-sized, stable lipid nanoparticle for the efficient delivery of siRNA to human immune cell lines. Sci Rep (2016) 6:37849. doi: 10.1038/srep37849

102. Oyer JL, Pandey V, Igarashi RY, Somanchi SS, Zakari A, Solh M, et al. Natural killer cells stimulated with PM21 particles expand and biodistribute in vivo: Clinical implications for cancer treatment. Cytotherapy (2016) 18 (5):653-63. doi: 10.1016/j.jcyt.2016.02.006

103. Hillman Y, Lustiger D, Wine Y. Antibody-based nanotechnology. Nanotechnology (2019) 30(28):282001. doi: 10.1088/1361-6528/ab12f4

104. Ning ST, Lee SY, Wei MF, Peng CL, Lin SY, Tsai MH, et al. Targeting Colorectal Cancer Stem-Like Cells with Anti-CD133 Antibody-Conjugated SN-38 Nanoparticles. ACS Appl Mater Interf (2016) 8(28):17793-804. doi: 10.1021 /acsami.6b04403

105. Mondal L, Mukherjee B, Das K, Bhattacharya S, Dutta D, Chakraborty S, et al. CD-340 functionalized doxorubicin-loaded nanoparticle induces apoptosis and reduces tumor volume along with drug-related cardiotoxicity in mice. Int J Nanomedicine (2019) 14:8073-94. doi: 10.2147/IJN.S220740

106. Guo D, Xu P, Chen D, Wang L, Zhu Y, Zuo Y, et al. Daunorubicin-Loaded CdTe QDs Conjugated with Anti-CD123 mAbs: A Novel Delivery System for Myelodysplastic Syndromes Treatment. Int J Nanomed (2020) 15:521-36. doi: $10.2147 /$ IJN.S233395

107. Shi X, Cheng Q, Hou T, Han M, Smbatyan G, Lang JE, et al. Genetically Engineered Cell-Derived Nanoparticles for Targeted Breast Cancer 
Immunotherapy. Mol Therapy: J Am Soc Gene Ther (2020) 28(2):536-47. doi: 10.1016/j.ymthe.2019.11.020

108. Peng J, Chen J, Xie F, Bao W, Xu H, Wang H, et al. Herceptin-conjugated paclitaxel loaded PCL-PEG worm-like nanocrystal micelles for the combinatorial treatment of HER2-positive breast cancer. Biomaterials (2019) 222:119420. doi: 10.1016/j.biomaterials.2019.119420

109. Kitano S, Kageyama S, Nagata Y, Miyahara Y, Hiasa A, Naota H, et al. HER2specific T-cell immune responses in patients vaccinated with truncated HER2 protein complexed with nanogels of cholesteryl pullulan. Clin Cancer Res (2006) 12(24):7397-405. doi: 10.1158/1078-0432.CCR-06-1546

110. Chen $\mathrm{CH}, \mathrm{Wu}$ YJ, Chen JJ. Photo-thermal therapy of bladder cancer with Anti-EGFR antibody conjugated gold nanoparticles. Front Biosci (2016) 21:1211-21. doi: $10.2741 / 4451$

111. Liszbinski RB, Romagnoli GG, Gorgulho CM, Basso CR, Pedrosa VA, Kaneno R. Anti-EGFR-Coated Gold Nanoparticles In vitro Carry 5Fluorouracil to Colorectal Cancer Cells. Materials (2020) 13(2):375. doi: 10.3390/ma13020375

112. Mamot C, Ritschard R, Wicki A, Stehle G, Dieterle T, Bubendorf L, et al. Tolerability, safety, pharmacokinetics, and efficacy of doxorubicin-loaded anti-EGFR immunoliposomes in advanced solid tumours: a phase 1 doseescalation study. Lancet Oncol (2012) 13(12):1234-41. doi: 10.1016/S14702045(12)70476-X

113. Russell LM, Hultz M, Searson PC. Leakage kinetics of the liposomal chemotherapeutic agent Doxil: The role of dissolution, protonation, and passive transport, and implications for mechanism of action. J Controlled Release (2018) 269:171-6. doi: 10.1016/j.jconrel.2017.11.007

114. Schiller GJ, Damon LE, Coutre SE, Hsu P, Bhat G, Douer D. High-Dose Vincristine Sulfate Liposome Injection, for Advanced, Relapsed, or Refractory Philadelphia Chromosome-Negative Acute Lymphoblastic Leukemia in an Adolescent and Young Adult Subgroup of a Phase 2 Clinical Trial. J Adolesc Young Adult Oncol (2018) 7(5):546-52. doi: 10.1089/jayao.2018.0041

115. Sasaki K, Kantarjian H, Wierda W, Ravandi-Kashani F, Jorgensen J, Wang $\mathrm{SA}$, et al. Phase 2 study of hyper-CMAD with liposomal vincristine for patients with newly diagnosed acute lymphoblastic leukemia. Am J Hematol (2020) 95(7):734-9. doi: 10.1002/ajh.25784

116. Passero FCJr., Grapsa D, Syrigos KN, Saif MW. The safety and efficacy of Onivyde (irinotecan liposome injection) for the treatment of metastatic pancreatic cancer following gemcitabine-based therapy. Expert Rev Anticancer Ther (2016) 16(7):697-703. doi: 10.1080/14737140.2016.1192471

117. Tucci ST, Kheirolomoom A, Ingham ES, Mahakian LM, Tam SM, Foiret J, et al. Tumor-specific delivery of gemcitabine with activatable liposomes. J Controlled Release (2019) 309:277-88. doi: 10.1016/j.jconrel.2019.07.014

118. Nassir AM, Ibrahim IAA, Md S, Waris M, Tanuja, Ain MR, et al. Surface functionalized folate targeted oleuropein nano-liposomes for prostate tumor targeting: Invitro and invivo activity. Life Sci (2019) 220:136-46. doi: 10.1016/j.lfs.2019.01.053

119. Choi SH, Byeon HJ, Choi JS, Thao L, Kim I, Lee ES, et al. Inhalable selfassembled albumin nanoparticles for treating drug-resistant lung cancer. J Controlled Release (2015) 197:199-207. doi: 10.1016/j.jconrel.2014.11.008

120. Hoogenboezem EN, Duvall CL. Harnessing albumin as a carrier for cancer therapies. Adv Drug Deliv Rev (2018) 130:73-89. doi: 10.1016/j.addr.2018.07.011

121. Hyun H, Park J, Willis K, Park JE, Lyle LT, Lee W, et al. Surface modification of polymer nanoparticles with native albumin for enhancing drug delivery to solid tumors. Biomaterials (2018) 180:206-24. doi: 10.1016/j.biomaterials. 2018.07.024

122. Onafuye H, Pieper S, Mulac D, Cinatl JJr., Wass MN, Langer K, et al. Doxorubicin-loaded human serum albumin nanoparticles overcome transporter-mediated drug resistance in drug-adapted cancer cells. Beilstein J Nanotechnol (2019) 10:1707-15. doi: 10.3762/bjnano.10.166
123. Cho H, Gao J, Kwon GS. PEG-b-PLA micelles and PLGA-b-PEG-b-PLGA sol-gels for drug delivery. J Controlled Release (2016) 240:191-201. doi: 10.1016/j.jconrel.2015.12.015

124. Pacheco PA, Rodrigues LNC, Ferreira JFS, Gomes ACP, Verissimo CJ, Louvandini $\mathrm{H}$, et al. Inclusion complex and nanoclusters of cyclodextrin to increase the solubility and efficacy of albendazole. Parasitol Res (2018) 117 (3):705-12. doi: 10.1007/s00436-017-5740-3

125. Schmidt KT, Peer CJ, Huitema ADR, Williams MD, Wroblewski S, Schellens JHM, et al. Measurement of NLG207 (formerly CRLX101) nanoparticlebound and released camptothecin in human plasma. J Pharm Biomed Anal (2020) 181:113073. doi: 10.1016/j.jpba.2019.113073

126. Chao J, Lin J, Frankel P, Clark AJ, Wiley DT, Garmey E, et al. Pilot trial of CRLX101 in patients with advanced, chemotherapy-refractory gastroesophageal cancer. J Gastrointest Oncol (2017) 8(6):962-9. doi: 10.21037/jgo.2017.08.10

127. Chen YF, Wang YH, Lei CS, Changou CA, Davis ME, Yen Y. Host immune response to anti-cancer camptothecin conjugated cyclodextrin-based polymers. J Biomed Sci (2019) 26(1):85. doi: 10.1186/s12929-019-0583-0

128. Uenaka A, Wada H, Isobe M, Saika T, Tsuji K, Sato E, et al. T cell immunomonitoring and tumor responses in patients immunized with a complex of cholesterol-bearing hydrophobized pullulan (CHP) and NYESO-1 protein. Cancer Immunity (2007) 7:9.

129. Ishihara M, Tono Y, Miyahara Y, Muraoka D, Harada N, Kageyama S, et al. First-in-human phase I clinical trial of the NY-ESO-1 protein cancer vaccine with NOD2 and TLR9 stimulants in patients with NY-ESO-1-expressing refractory solid tumors. Cancer Immunol Immunother: CII (2020) 69 (4):663-75. doi: 10.1007/s00262-020-02483-1

130. Yi Y, Zhou Z, Shu S, Fang Y, Twitty C, Hilton TL, et al. Autophagy-assisted antigen cross-presentation: Autophagosome as the argo of shared tumorspecific antigens and DAMPs. Oncoimmunology (2012) 1(6):976-8. doi: $10.4161 /$ onci.20059

131. Page DB, Hulett TW, Hilton TL, Hu HM, Urba WJ, Fox BA. Glimpse into the future: harnessing autophagy to promote anti-tumor immunity with the DRibbles vaccine. J Immunother cancer (2016) 4:25. doi: 10.1186/s40425016-0130-4

132. Ye W, Xing Y, Paustian C, van de Ven R, Moudgil T, Hilton TL, et al. Crosspresentation of viral antigens in dribbles leads to efficient activation of virusspecific human memory T cells. J Trans Med (2014) 12:100. doi: 10.1186/ 1479-5876-12-100

133. Anzaghe M, Schulke S, Scheurer S. Virus-Like Particles as Carrier Systems to Enhance Immunomodulation in Allergen Immunotherapy. Curr Allergy Asthma Rep (2018) 18(12):71. doi: 10.1007/s11882-018-0827-1

134. Zepeda-Cervantes J, Ramirez-Jarquin JO, Vaca L. Interaction Between Virus-Like Particles (VLPs) and Pattern Recognition Receptors (PRRs) From Dendritic Cells (DCs): Toward Better Engineering of VLPs. Front Immunol (2020) 11:1100. doi: 10.3389/fimmu.2020.01100

135. Qian C, Liu X, Xu Q, Wang Z, Chen J, Li T, et al. Recent Progress on the Versatility of Virus-Like Particles. Vaccines (2020) 8(1):139. doi: 10.3390/ vaccines 8010139

Conflict of Interest: The authors declare that the research was conducted in the absence of any commercial or financial relationships that could be construed as a potential conflict of interest.

Copyright $\odot 2020 \mathrm{Li}$, Peng, Wu, Quan, Li, Lu and Cui. This is an open-access article distributed under the terms of the Creative Commons Attribution License (CC BY). The use, distribution or reproduction in other forums is permitted, provided the original author(s) and the copyright owner(s) are credited and that the original publication in this journal is cited, in accordance with accepted academic practice. No use, distribution or reproduction is permitted which does not comply with these terms. 